\title{
Análise comparativa do diálogo intertextual entre literatura e cómic: Los que quedan (2019), de Josep Busquet e Alex Xöul
}

\author{
Rocío G-Pedreira \\ CIEC-IE-Universidade do Minho/ \\ ICE-Universidade de Santiago de Compostela \\ https://orcid.org/0000-0002-5102-5078
}

[Recibido, 2 outubro 2020; aceptado, 14 decembro 2020]

[G-Pedreira, R. (2020). Análise comparativa do diálogo intertextual entre literatura e cómic: Los que quedan (2019), de Josep Busquet e Alex Xöul. Boletín Galego de Literatura, 57, "Notas", 45-69]

DOl http://dx.doi.org/10.15304/bgl.57.7146

RESUMO O obxectivo principal desta nota é a indagación arredor da maneira na que se artella o diálogo intertextual entre a literatura e o cómic no caso concreto da novela gráfica Los que quedan (2019), da autoría de Josep Busquet (Barcelona, 1975) e Alex Xöul (Barcelona, 1984), a través dunha análise comparativa dos motivos característicos dos open/alternative worlds (Nikolajeva, 1988, 2012) e a retórica das portal-quest fantasies (Mendlesohn, 2008; Levy e Mendlesohn, 2016) que son abordados dende unha óptica novidosa e pouco común para a construción da obra estudada. O traballo dá conta dos transvases intermediais que se suceden con recorrencia entre produtos artísticos dirixidos a adultos e/ou ao público infantil e xuvenil que dan como resultado obras con construcións análogas cuxo polisistema de acollida vén determinado polo desprazamento do protagonismo das crianzas a favor dunha construción centrada na visión, intereses e preocupacións dos adultos, que se converten no receptor implícito do produto resultante.

PALABRAS CHAVE: Literatura fantástica; intertextualidade; intermedialidade; novela gráfica; literatura comparada.

ABSTRACT The main aim of this note is to investigate the way in which the intertextual dialogue between literature and comics is carried out in the specific case of the graphic novel Los que quedan (2019), by Josep Busquet (Barcelona, 1975) and Alex Xöul (Barcelona, 1984), through a comparative analysis of the characteristic motifs of the open/ alternative worlds (Nikolajeva, 1988, 2012) and the rhetorics of the portal-quest fantasies (Mendlesohn, 2008; Levy and Mendlesohn, 2016) which are approached from a new and unusual perspective for the construction of the work studied. The work shows the recurrent intermediate transfers between artistic products aimed to adults and/or at children and young people, which result in works with similar constructions whose reception system is determined by the displacement of the protagonism of the children in favour of a construction centred on the vision, interests and concerns of the adults, who become the implicit recipients of the resulting product.

KEYWORDS: Fantasy literature; intertextuality; intermediality; graphic novel; comparative literature. 


\section{Introdución}

A dificultade inherente ao desenvolvemento teórico da literatura fantástica vén provocada pola existencia de dous grupos de estudosos diferenciados con visións diferentes acerca de que obras poden pertencer ou non a esta modalidade xenérica: os restritivos, entre os que se atopa Tzvetan Todorov (1970/1994) e outros teóricos do fantástico que seguiron en gran medida a súa proposta (Furtado, 1980; González Salvador, 1984; Jackson, 1986; Camacho, 2003 ou Roas, 2008, 2011, 2013, coordinador de monográficos sobre a temática en 2001 e 2018) e os integradores, entre os cales destaca na actualidade Farah Mendlesohn, cuxa proposta de taxonomía do fantástico recollida en Rethorics of fantasy (2008) se realiza tomando como principal referencia os estudos de Brian Attebery (1980, 1992, 2014).

Segundo Todorov (1994, p. 24), "lo fantástico es la vacilación experimentada por un ser que no conoce más que las leyes naturales, frente a un acontecimiento aparentemente sobrenatural”. O tempo de dúbida é o único momento de existencia do fantástico que termina por decantarse por un dos subxéneros limítrofes a través da decisión do personaxe e/ou lector: se as leis da realidade quedan intactas estaríase no campo de influencia do estraño; se é necesario admitir novas leis para explicar o fenómeno, a obra pertencería ao subxénero do marabilloso. Un dos maiores inconvenientes da aplicación desta proposta é, segundo Lucas Gagliardi (2020), a súa incapacidade para poder explicar a configuración do fantástico en textos máis recentes que responden á definición recollida en The Encyclopedia of Fantasy (Clute e Grant [eds.], 1997) de texto fantástico como "a self-coherent narrative" (p. 338), na cal se mostra de maneira evidente ou suxerida a dualidade entre o mundo primariorealista e o secundario-fantástico. Nesta mesma liña, Mendlesohn (2008) non se interesa por realizar unha definición do fantástico e artella unha proposta taxonómica da retórica destes relatos a través da cal se poden estudar textos infantís ${ }^{1}$ ou para adultos, propios do subcampo de gran produción ou de produción restrinxida ${ }^{2}$, polo que relaciona catro modos ou categorías do fantás-

1 A autora publica xunto a Michael Levy un monográfico onde aplica a proposta desenvolta pola profesora para o estudo das obras literarias infantís e xuvenís fantásticas, titulado Children's Fantasy Literatura. An introduction (2016).

2 Segundo o Dicionario de Termos Literarios (DiTerLi) (2009) do Equipo Glifo (http://bernal.cirp.gal/ ords/ $f$ ? $p=106: 1$ ), a estrutura do campo literario depende do grao de autonomía que manteñan con respecto ao campo de poder, delimitándose deste xeito dous subcampos diferenciados: o da gran produción, que goza de pouca autonomía ao se guiar polo beneficio económico que articula 
tico: portal-quest fantasy, que agrupa as nocións de portal fantasy, un mundo fantástico ao que se accede a través dun portal, e quest fantasy, cando o protagonista parte dunha vida ordinaria e entra en contacto directo co fantástico a partir dunha viaxe exploratoria; inmersive fantasy, cando o fantástico non recibe ningún tipo de explicación xa que está normalizado dentro da realidade da ficción; intrusion fantasy, cando o fantástico irrompe na dinámica do mundo da ficción, entendido como ordinario e predicible; e liminal fantasy, cando o fantástico dá sinais de existencia, pero non se confirma como tal; e os irregulars, onde a autora coloca as obras que non contan con suficientes puntos en común como para crear unha nova categoría.

No caso das portal fantasies tende a facerse manifesta a existencia dun mundo secundario con entidade en si mesmo (como Wonderland, Neverland ou Narnia) ao cal se despraza o personaxe protagonista. Por esta razón, Maria Nikolajeva (1988) realiza unha tipoloxía de relatos fantásticos onde inclúe a noción dos openworlds, cando o mundo primario e o secundario están conectados e ambos están recollidos de maneira explícita na ficción, xa que o lector acompaña ao protagonista nas súas viaxes de ida e volta. Nun artigo posterior, a mesma autora fala en termos xerais dos alternative worlds para referirse á multitude de posibilidades de construción de mundos secundarios fantásticos e de formas de interactuar co primario (Nikolajeva, 2012).

Noutra orde de cousas, o debate arredor da etiqueta de "novela gráfica" está de plena actualidade e os diversos estudos que se foron sucedendo na última década (García, 2010; Trabado, 2012; Baetens e Frey, 2015; Duncan e Smith, 2017; Tabachnick, 2017; Conde Aldana, 2019) coinciden en que a súa vixencia responde ao aumento de consideración e do éxito comercial desta forma particular de lectura e a rotura coas convencións características dos libros de historietas tradicionais chegados do ámbito norteamericano, así como a importancia do recoñecemento do Maus (1980) de Art Spiegelman, primeira novela gráfica gañadora dun Premio Pulitzer en $1992^{3}$. En efecto, Duncan e Smith (2017, p. 8) afirman que "Graphic novels are the long-form

o campo de poder; e o campo de produción restrinxida, que goza dun alto grao de autonomía promovendo o aumento do prestixio e a lexitimidade artística das obras.

3 Non obstante, cremos necesario destacar a desconfianza de tanto Spiegelman como de Alan Moore, guionista de Wathcmen (1986-1987), do proveitoso que pode chegar a ser o neoloxismo de "novela gráfica" debido a que o seu nacemento e auxe responde a aspectos principalmente comerciais (Baetens e Frey, 2015). 
of a mode of communication called comics", idea que Tabachnick (2017, p. 26) desenvolve do seguinte xeito:

In contrast to the popular mass-market comics, which have usually been severely restricted in both form and content by commercial constraints, the graphic novel is an extended comic book freed of all restrictions on form and content and capable of tackling all of the issues that writing and art for adults have always dealt with, using all of the literary and artistic resources available to any writer or artist. But it is a form that is clearly based on the technigques of comics, and readers have to read both words and pictures to make sense of it.

$\mathrm{Na}$ liña do estudo teórico e histórico sobre novela gráfica de Santiago García (2010, p. 16) no cal deixa claro que con este termo non nos referimos "a un cómic con características formales o narrativas de novela literaria, ni tampoco a un formato determinado, sino, sencillamente, a un tipo de cómic adulto moderno que reclama lecturas y actitudes distintas del cómic de consumo tradicional", a proposta de definición flexíbel de Baetens e Frey (2015) foi considerada para este estudo como a máis axeitada. Segundo os autores, a novela gráfica, afastada da exclusión cultural que sufriu o universo dos cómics, é definida como un medio: "we propose that the graphic novel as a medium is part of other, more-encompassing cultural fields and practices (graphic literature, visual storytelling), and that within these fields and practices there are rarely clear-cut distinctions between types and categories" (Baetens e Frey, 2015, p. 8). Ademais, propoñen catro niveis de descrición: o nivel formal, no cal explican que a novela gráfica non racha totalmente coas regras estabelecidas pola industria do cómic, mais explora e xoga con elas para dar lugar a unha nova forma innovadora de facer cómic onde destaca a individualización dos estilos artísticos dos creadores; o nivel de contido, debido a que estas obras tenden a inclinarse por historias máis realistas e dirixidas a público adulto; o nivel de formato de publicación, no cal explican que as novelas gráficas apostan polo formato libro propio da novela tradicional (tanto en tamaño, cuberta, papel, número de páxinas etc.), deixando atrás a serialización; e o nivel da produción e distribución, facendo referencia á importancia da creación de editoriais independentes especializadas e ao éxito conseguido como fórmula editorial que supuxo a conquista de novos públicos.

En todo caso, o certo é que o interese polo mundo do cómic no ámbito da investigación científica está moi vixente na actualidade e sucédense os estudos que o traballan dende distintas ópticas, como os transvases intertextuais 
e intermediais con outras artes como a literatura ou o cine (Bendit Saltzman, 2017; Booker, 2017; Pineda, 2018; Medina Rodríguez, 2020; Pina Arrabal, 2020; González de la Llana, 2020; García-Conde Maestre, 2020) ou as posibilidades pedagóxicas destas obras nas aulas (Chacón, 2015, 2016; Carter, 2017; Paré e Soto-Pallarés, 2017; Lizarazú Bernal, 2018; Weschenfelder, 2020; Mena Araya, 2020).

A partir do marco teórico introducido, ao longo desta nota analizarase a construción argumental da novela gráfica Los que quedan (2019), con guión de Josep Busquet e debuxo e cor de Alex Xöul, partindo da súa consideración como un xogo de dialoxismo intertextual (Stam, 2000) coa categoría das portal fantasies e dos openworlds. A obra comeza unha noite na que o seu protagonista, un neno de nome Ben, é visitado por unha estraña criatura que accede ao seu dormitorio a través da ventá para pedirlle que o acompañe ao seu reino, o cal está en perigo e só pode ser salvado por el. A emoción da aventura lonxe do fogar e dos adultos responsables ao seu cargo é demasiado tentadora como para rexeitar a oferta, e ambos saen voando pola fiestra cara ao seu destino. Non obstante, a partir deste momento é cando a narración toma un rumbo pouco habitual, xa que no lugar de acompañar a Ben, o lector queda no mundo primario xunto os seus pais e descobre a outra cara da moeda, a historia dos adultos que quedan atrás, cuxa trama se complica debido ao abandono da visión fantástica do mundo, a necesidade do raciocinio constante e a desconfianza como norma, que parecen ir da man do proceso de maduración do individuo cara á vida adulta.

Polo tanto, o obxectivo da nota é indagar a maneira na que se artellan as distintas conexións intertextuais desta obra coas categorías do fantástico citadas a través da análise rigorosa dalgúns dos fragmentos que compoñen o arco argumental da historia. Ademais, o estudo botará luz sobre a identificación da obra de Busquet e Xöul coa tipoloxía das novelas gráficas e as estratexias empregadas polos autores para reescribir fórmulas típicas das narrativas fantásticas infantoxuvenís e crear un produto cuxo público implícito son os adultos.

\section{Los que quedan: o lado escuro da fantasía}

As viaxes a mundos fantásticos que emprenden os protagonistas infantoxuvenís de multitude de obras clásicas da literatura como Alicia, Wendy, os irmáns Pevensey ou Dorothy son posíbeis grazas a que son "os elixidos”, os 
heroes cuxo destino é salvar os habitantes dunha realidade que non é a súa e pola que desenvolven un forte sentimento de pertenza. Ademais, a correspondencia cun estadio evolutivo previo á idade adulta é un factor determinante que os fai idóneos, xa que todo o desenvolvemento da trama precisa do afastamento das restricións impostas pola necesidade de protección da infancia dos adultos ao seu cargo. Non obstante, a impresión que eles teñen das viaxes que emprenden os seus fillos non son tomadas en consideración nin importan realmente para a trama, xa que os protagonistas cumprirán o seu destino e volverán ao mundo primario logo dunha viaxe tamén de madureza que dalgún xeito mellorará a súa capacidade de adaptabilidade social ao mundo ao que pertencen. É dicir, as consecuencias destas viaxes son en esencia positivas e tenden a pasar desapercibidas polos adultos, relacionándoas en moitas ocasións con fabulacións ou cunha resposta natural á visión simbólica do mundo das primeiras idades.

Así, a fantasía é considerada un recurso ao alcance do creador para salientar o mundo da infancia, para impartir xustiza, para rachar coas limitacións da realidade e reflexionar sobre ela a través dun afastamento consciente. Nesta liña pronunciábase tamén Jacqueline Held (1985, p. 18) para realizar unha férrea defensa da fantasía e a súa importancia para o desenvolvemento integral dos máis novos: "¿lo irreal de lo fantástico, es en verdad un irreal? Lo fantástico, ¿nos conmovería?; la obra fantástica, ¿encontraría lectores si éstos no reunieran las aspiraciones, las necesidades, las experiencias que también llevamos en nosotros en diverso grado, oscuras y semiignoradas quizá, pero muy reales, sin embargo?".

Mais que sucedería se a óptica dende a que é narrada a historia se desprazara cara aos intereses e punto de vista dos adultos? Busquet e Xöul parecen artellar unha posíbel resposta a esta pregunta a través da construción argumental de Los que quedan (2019), publicada en español pola editorial especializada en cómic Ponent $\mathrm{Mon}^{4}$, que xira arredor do lado escuro da fantasía e de como a súa evolución característica nos clásicos mencionados é truncada até o punto de supoñer un final desgraciado para todos os adultos implicados, tanto para os pais de Ben como para o propio rapaz xa feito un home.

\footnotetext{
4 A obra foi inicialmente publicada en francés no 2018 por Editions Delcourt baixo o título Ceux qui restent.
} 
A partir dun deseño metodolóxico mixto baseado na análise de contido (Krippendorff, 1990; Bardin, 1991; Pérez, 1994; Mayring, 2000; Cáceres, 2003; Richard, 2009, Piñeiro-Naval, 2020), que utiliza instrumentos e procedementos obxectivos de descrición para o tratamento explícito e implícito do contido das mensaxes non só verbais (López Noguero, 2002; Francescutti, 2019), a análise da novela gráfica será guiada polo desenvolvemento da propia narración. Deste xeito, foron identificadas e analizadas con detrimento un total de oito secuencias que funcionan como unidades narrativas estruturadas que corresponden ás catro viaxes de ida e volta que Ben realiza ao mundo fantástico, así como dúas escenas finais que mostran o desenlace de dous personaxes fundamentais da historia: o periodista Alan Lesstone e o propio Ben. O modelo de análise aplicado segue as propostas de Sulbarán Piñeiro (2000), Sánchez Noriega (2000) e López Fernández (2003) con respecto ao estudo de películas e reescrituras fílmicas a partir da semiótica do relato e a narrativa fílmica, quen inciden na necesidade da construción da scaletta, unha estrutura desagregada en escenas que segmenta as películas en secuencias con títulos ou palabras-cobertura que engloban o asunto. Ademais, Sánchez Noriega (2000) destaca que esta segmentación é imprescindíbel para o caso concreto das películas co obxectivo de recrear por escrito a información audiovisual, o cal consideramos extrapolábel á linguaxe do cómic.

A historia está contextualizada en todo momento no mundo real-primario. O foco de atención está en Ben até que viaxa ao mundo fantástico-secundario, momento no que se traslada aos seus pais. En efecto, a primeira marcha de Ben (pp. 5-16) inicia na primeira páxina da novela gráfica cando un ser máxico denominado Wumple entra pola noite á súa habitación solicitándolle axuda para salvar o seu reino fantástico, Auxfanthas, xa que só el pode facelo. O narrador -cuxas intervencións están inseridas en cartelas de cor rosa clara menos redondeados que os que recollen as palabras dos personaxes- xa ofrece indicios ao lector sobre o cambio no punto de vista da historia adiantando que o soño feito realidade de Ben leva parello un auténtico pesadelo para os seus pais (figura 1).

A partir deste momento a historia vai mostrando as reaccións dos personaxes, que están en relación directa coa información da que dispoñen. Estes poden ser clasificados en tres ámbitos: o privado, onde se atopan os pais de Ben, Edward e Susan; o público, que agrupa os veciños e a prensa; e o restrinxido, que corresponde á policía, cuxa información é maior e máis sofisti- 
cada ca dos individuos do ámbito público xa que se nutre do que lle contan os pais do rapaz, pero está baixo segredo de sumario. Nesta primeira secuencia que corresponde á primeira marcha de Ben, as reaccións dos personaxes do ámbito público e restrinxido son similares, conmovidos e con plena confianza na inocencia dos pais e na sinceridade do seu pesar.
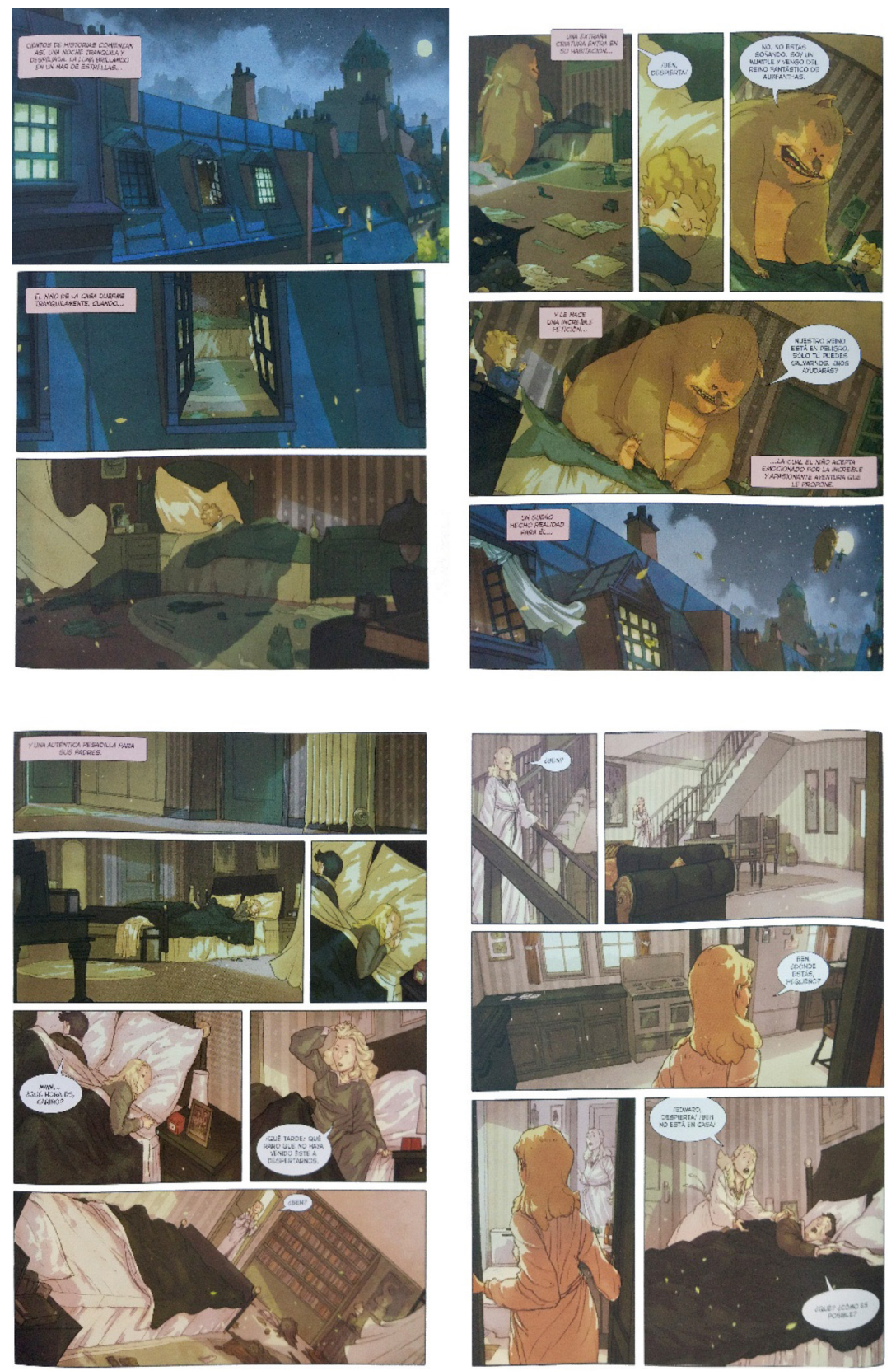

Figura 1. Páxinas 5-8 de Los que quedan (2019). 
Cando Edward e Susan xa empezan a dalo todo por perdido, Ben regresa de noite e aparece no seu cuarto. Deste xeito comeza a segunda secuencia identificada, a primeira volta de Ben (pp. 17-34). O rapaz retorna pletórico e fálalles aos seus pais da incríbel aventura que viviu nun mundo fantástico cheo de maxia. Edward e Susan móstranse estrañados, especialmente polo feito de que para Ben pasaran só uns días, mentres para eles foran meses de angustia, pero están felices porque o único que lles importa é que o seu fillo está de volta. Os periodistas volven interesarse polo caso con alegría, mais un deles, Alan Lesstone, non cesa de advertir no seu programa radiofónico de que a prensa e a policía non están cuestionándose a rareza da reaparición do neno e de que hai algo turbio detrás que implica os pais de Ben, mais ninguén lle presta moita atención. Neste momento é cando os rumores xurdidos fan que se afasten as opinións dos personaxes do grupo correspondente ao ámbito público: por un lado estaría a maioría da prensa e os veciños e por outro Alan Lesstone.

En secuencias sucesivas queda patente o tratamento adulto da desaparición de Ben. Entre outras, destaca na que Edward e Susan, incitados polos inspectores, levan o rapaz á psiquiatra. Logo da sesión, a profesional entrevístase con eles e cóntalles que está segura de que as historias de Ben son un escudo de protección tras o que se agocha un evento traumático que antes ou despois lle acabará producindo secuelas ${ }^{5}$. Ademais, opina que a sofisticación do relato pode ser proporcional á gravidade do trauma. A pesar disto, os inspectores deciden arquivar o caso, convencidos da inocencia dos pais. Neste momento da historia é cando aparecen en escena Arthur e Estela, quen visitan os pais de Ben para falarlles da "Asociación de padres de niños aventureros" (APNA) que preside o home. O matrimonio afirma que cren que a historia que conta Ben é certa. Tamén lles relatan que este tipo de desaparicións son moi comúns, que o seu fillo vivira o mesmo e que Ben volvería desaparecer sen que eles puideran evitalo. Non obstante, os pais de Ben non cren na súa verdade e rematan botándoos.

5 Este mesmo xogo de racionalización das viaxes a mundos fantásticos co obxectivo de crear unha obra cun tratamento da temática máis adulto é o que leva a cabo Seanan McGuire na súa galardoada novela Every heart a doorway (2016), cuxa construción foi analizada brevemente na nota "A complexidade do modelo fantástico intertextual de Cada corazón, un umbral" (2019), de Rocío G-Pedreira. 
Unhas semanas despois da visita, Ben emprende a súa segunda marcha, comezando así a terceira secuencia da historia (pp. 35-59). O narrador indícalle ao lector que esta vez todo é distinto á anterior: os investigadores móstranse escépticos sobre o acontecido, preguntando sobre unha posíbel agresión ou maltrato por parte dos pais, e a prensa pregunta sen descanso. Distintos periódicos e programas radiofónicos comezan a falar do tema, o cal se tornara máis interesante para eles polo auxe dos rumores sobre a posíbel implicación dos pais. Así, o periodista Alan Lesstone, que anteriormente fora ignorado, gaña notoriedade e un público fiel cativado pola noticia. Deste xeito, as dúas posicións enfrontadas dos personaxes do ámbito público iguálanse e a policía comeza a sospeitar. En efecto, ao longo da secuencia vemos como a división de pareceres tamén afecta aos inspectores que discuten sobre que facer co caso: Phil opta por cerralo, aínda que desconfía dos pais, mentres Laura cre na súa inocencia.

Desolados, sen apoio e máis sós que nunca, os pais de ben póñense en contacto con Arthur e Estela e van visitalos. A parella explícalles que o seu fillo viaxara repetidas veces a un mundo fantástico mentres eles envellecían e o rapaz se mantiña novo, e que o mesmo lle acontecera a moitas familias, aínda que cada mundo era distinto e tiña as súas propias normas. Tamén lles comentan que a asociación nacera para dar apoio e ofrecer recomendacións e protocolos de como actuar nestas situacións. O contacto continuo dos pais de Ben coa asociación fai que se converta nunha gran familia para eles, e os seus integrantes contan con información privilexiada que os leva a formar parte da categoría estabelecida para o ámbito privado. Por outra parte, nunha das reunions da APNA á que Edward e Susan acoden tempo despois, dúas nais contan as súas historias e mostran así as dúas posturas enfrontadas que dan conta do distanciamento das perspectivas infantil e adulta con respecto ás viaxes a mundos fantásticos: unha delas explica que dende o regreso da súa filla, logo da segunda viaxe a un planeta descoñecido, ela e o seu marido fan garda para que non volva marchar, motivo polo cal o pai non puidera acudir esa noite á reunión; por outra parte, Edna móstrase moito máis conciliadora e afirma estar contenta de que o seu fillo estea facendo algo bo e entende que tomara a decisión de marchar, porque se lle sucedera a ela cando era unha nena faría o mesmo sen pensar nos pais: 

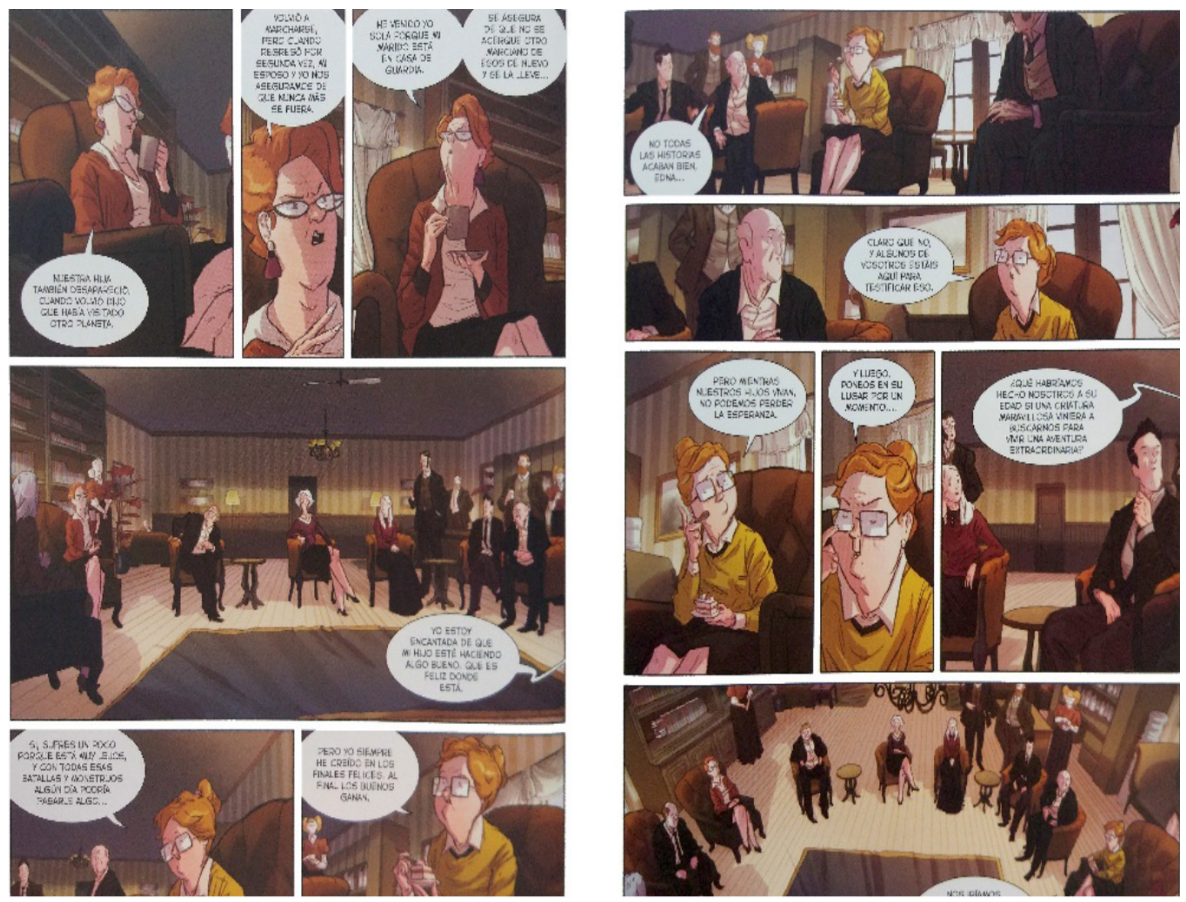

Figura 2. Páxinas 50-51 de Los que quedan (2019).

Deste xeito chegamos á segunda volta de Ben (pp. 60-76), na cal o proceder dos pais, a tenor dos novos coñecementos cos que contan, é totalmente distinto. Edward e Susan seguen as pautas do protocolo da APNA e non poñen en aviso a ninguén, mais unha veciña alerta a Laura e os inspectores visitan a casa familiar, onde a prensa se amoreara para lanzarlles preguntas inquisitivas. A psiquiatra infantil confirma que Ben está ben, sen sinais de abuso ou traumatismo, pero mantén a mesma historia. Unha vez máis os inspectores están desconcertados, e Phil está decidido a cerrar o caso. A recepción na prensa desta volta é distinta e non mostran moito interese, aínda que Lesstone continúa insistindo sobre as súas teorías nun programa nocturno. Os pais de Ben intentan continuar a súa vida con normalidade, pero todos os problemas dos que os advertira a asociación, derivados da diferencia de temporalidade do mundo, comezan a cumprirse: Ben non acaba de asumir que pasaran meses e non é capaz de reincorporarse á dinámica de clase, mentres soña con volver ao mundo fantástico. A profesora remata citando aos pais a unha reunión para recomendarlles que o matriculen nun centro de educación especial, polo que os pais deciden ter unha conversa con Ben para confirmar os seus medos de que está pensando en regresar. Nese momento vemos como a nai rompe a chorar, incapaz de agochar a súa desesperación: 

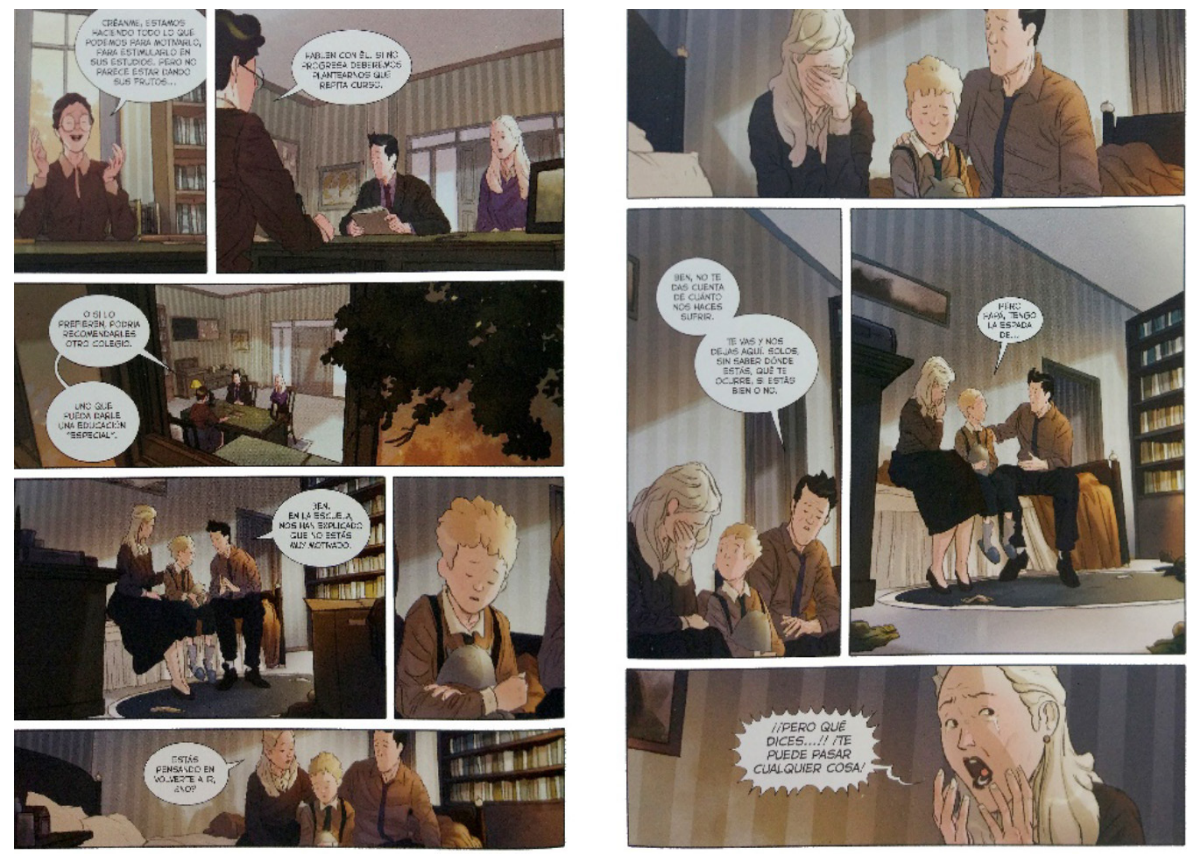

Figura 3. Páxinas 72-73 de Los que quedan (2019).

Non obstante, logo deste momento tenso a nai móstrase arrepentida e cariñosa, e suplícalle a Ben que non volva marchar. A partir de aí, os pais intentan facer todo o que poden para que o fillo deixe de pensar nese mundo, e programan plans divertidos en familia; mais cando días máis tarde van buscar a Ben para ir ao zoolóxico, descobren que o rapaz volvera desaparecer.

Ante a terceira marcha de Ben (pp. 77-102), os pais volven poñer en práctica as indicacións da asociación: compórtanse como se nada acontecera e avisan no colexio que decidiran matricular a Ben nun centro de educación especial, o cal xustifican entregando uns papeis falsos proporcionados pola asociación. Todo indica que o mundo enteiro non se dera conta de nada. Mais Edward e Susan viven desolados debido á falta do seu fillo, e acoden á asociación para atopar consolo. Non obstante, Susan non pode evitar vivir unha forte depresión que lle quita as ganas de todo, incluso de comer. Ademais, pese a que os veciños e os amigos cren a historia artellada polos pais, están cada vez máis afastados.

No caso da prensa, de novo destaca a figura de Alan Lesstone, quen se convertera nun reporteiro de éxito grazas ao caso de Ben. Nunha das escenas vese como dialoga coa súa secretaria sobre a necesidade que teñen de atopar 
un novo rumor ou escándalo do que tirar proveito, e por isto deciden retomar o caso de Ben. Así, interroga os veciños e familiares, incluso a profesora, mais o protocolo da asociación parece funcionar. Non obstante, Alan está decidido a crear unha boa historia e remata atopando unha muller que desconfía dos pais de Ben a través da cal reaviva os rumores e mediatiza o caso.

Ante a preocupación de Arthur e Elena e o desconsolo de Edward e Susan, os inspectores Phil e Laura volven visitar a casa de Ben. Os pais, desolados, contestan as mesmas preguntas outra vez e mostran todos os papeis que os apoian. Aínda que Laura confía na súa inocencia, decide seguir a Edward até o local da APNA e, cando sae da reunión, intercepta o home para preguntarlle sobre que estaba acontecendo. Edward non pode máis e cóntalle toda a verdade, e aínda que a muller queda estupefacta, o seu instinto dille que non está mentindo e decide non contarllo a Phil. Ao día seguinte na comisaría, Phil informa a Laura de que o do colexio era todo mentira e que tiña a orde xudicial para detelos. Cando por fin chega a policía á casa familiar, Lesstone espera ao pé da entrada para cubrir a noticia lanzando acusacións e xuramentos en contra dos pais de Ben. No momento que os inspectores entran para detelos, Susan sofre un infarto que a converte na primeira vítima mortal das viaxes do fillo.

O tempo segue pasando e Lesstone acada as súas mellores audiencias poñendo o público en contra de Edward, quen acode ao xuízo apoiado polos membros da asociación. A súa testemuña e a recente morte de Susan conmoven o xurado, que remata declarándoo inocente. Lesstone pregoa o seu descontento, mais a súa actitude demasiado agresiva acaba cansando os espectadores. Logo disto, Edward volve a un fogar que o martiriza, mais do que non pode marchar por se o pequeno Ben regresa. Afortunadamente recibe un apoio inesperado de parte da inspectora Laura, coa que comeza unha relación sentimental.

Logo de que a relación de Edward e Laura se afinca, Ben regresa de novo ao seu fogar dando comezo a secuencia correspondente á terceira volta do rapaz (pp. 103-109). O primeiro que fai cando ve o seu pai é preguntar pola nai. Edward tenlle que explicar todo o que pasara, feliz polo seu regreso, pero sen poder perdoarlle por completo o sucedido. Laura avisa á policía convencida de que crerían na súa palabra, mais acúsana de padecer o síndrome de Estocolmo e volven comezar as preguntas e as revisións médicas ao pequeno, 
cuxas conclusións relacionan o feito de que non medrara nada dende que desaparecera con algunha enfermidade descoñecida ou graves lesións psicolóxicas. Como ben indica o narrador, "FRENTE A LO INEXPLICABLE, ERA NECESARIO GUARDAR LAS APARIENCIAS” (p. 106).

Desta volta, a Ben resúltalle imposíbel volver á normalidade xa que os seus compañeiros son moito máis maiores, polo que o seu pai e Laura deciden que estude na casa. A pesar de que á prensa non lle interesa xa o tema, Lesstone insiste e especula sobre a implicación do goberno ou de marcianos. Aínda que o tempo fai que todo se tranquilice, Ben segue impactado polos cambios que atopa ao regreso e pensa a cotío en volver con Wumple. O seu pai advírteo e decide poñer en práctica os consellos de certos membros da asociación poñendo reixas nas ventás e apuntalando a porta do cuarto do rapaz, pero Ben séntese atrapado e cando llo recrimina a Edward brota de golpe o rancor contido, de maneira análoga a como o fixera con anterioridade no caso de Susan:
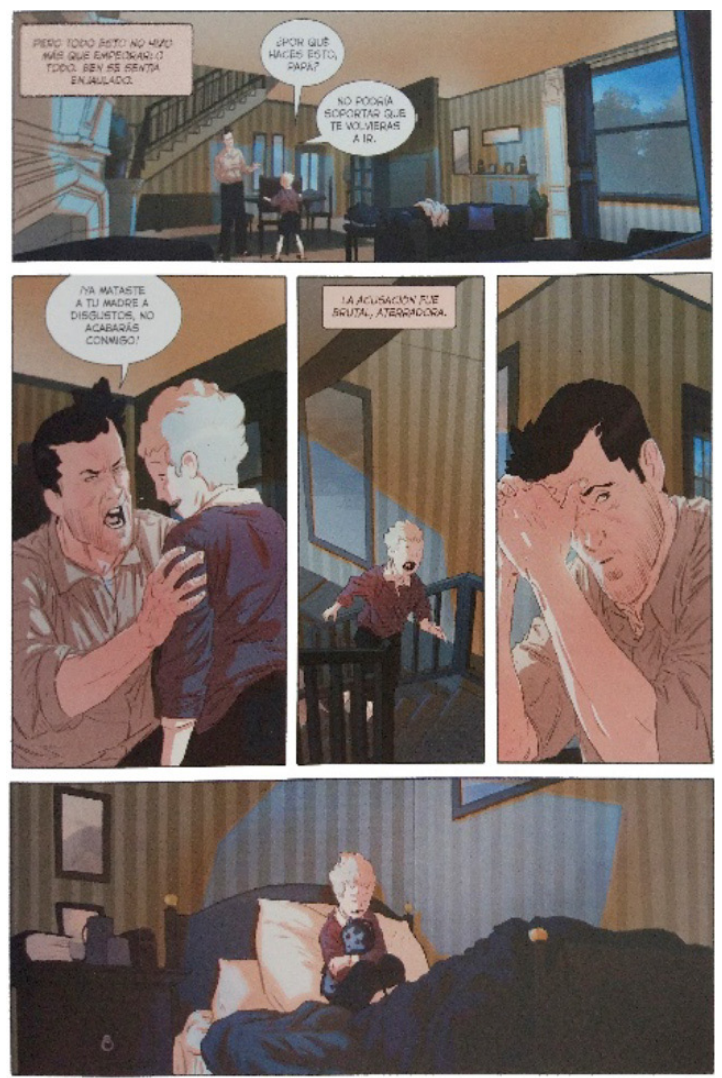

Figura 4. Páxina 109 de Los que quedan (2019). 
As dúas últimas secuencias da novela gráfica que corresponden á cuarta marcha de Ben (pp. 110-117) e o seu correspondente regreso (pp. 118-125) son moito máis curtas en extensión, mais paradoxicamente recollen o maior tramo temporal que prepara a narración para o desenlace. Nesta ocasión, Ben é perfectamente consciente do dano que supuxeran as súas marchas para os seus pais, pois foran os detonantes da morte de Susan, pero nunha carta que deixa no seu cuarto intenta xustificarse insistindo na importancia que ten a súa empresa: "SIENTO MUCHO EL DAÑO QUE TE VOY A HACER, PAPÁ, PERO DEBO MARCHARME UNA VEZ MÁS./ ME NECESITAN PARA SALVAR EL MUNDO, SÓLO YO PUEDO DETENER A LOS EJÉRCITOS DEL MAL. TIENES QUE ENTENDERLO./ SERÁ UN POCO PELIGROSO, PERO HE SALIDO DE COSAS PEORES. LA PIEDRA DE KAKRETT ME PROTEGE...” (p. 111).

Despois disto, Laura vese obrigada a avisar a Phil e intenta convencelo de que Edward non oculta nada. A pesar de que non a cre e pensa que está influenciada pola súa relación co pai de Ben, decide cerrar o caso, desesperado por como sucedera todo. A actitude dos compañeiros de Laura é distinta e non confian nela, polo que remata por dimitir e dedicarse por completo á parella. Ambos esperan o regreso de Ben, pero esta vez o tempo pasa e non hai rastro do rapaz, o cal afecta especialmente a Edward. A narración gráfica correspondente a esta secuencia resulta especialmente paradigmática para a consideración da obra, xa que as ilustracións -sen necesidade de diálogos- dan conta da evolución do estado do pai a través dun cambio de planos que van variando ao longo de catro viñetas: a primeira é un plano enteiro conxunto onde se mostra a Laura durmindo xunto a Edward, quen non pode conciliar o sono pensando no seu fillo; a seguinte viñeta recolle un plano enteiro, pero desta vez só se representa o home, tamén de noite, sentado na cama de Ben totalmente rendido; a continuación, unha viñeta a páxina completa mostra un plano xeral da parella contemplando o ceo dende o balcón, no cal Laura apoia a súa man nas costas do home intentando reconfortalo; finalmente, o gran plano xeral do ceo nocturno que ocupa unha dobre páxina adquire un valor dramático que salienta os estados de ánimo dos personaxes. Aquí recóllense as catro páxinas: 

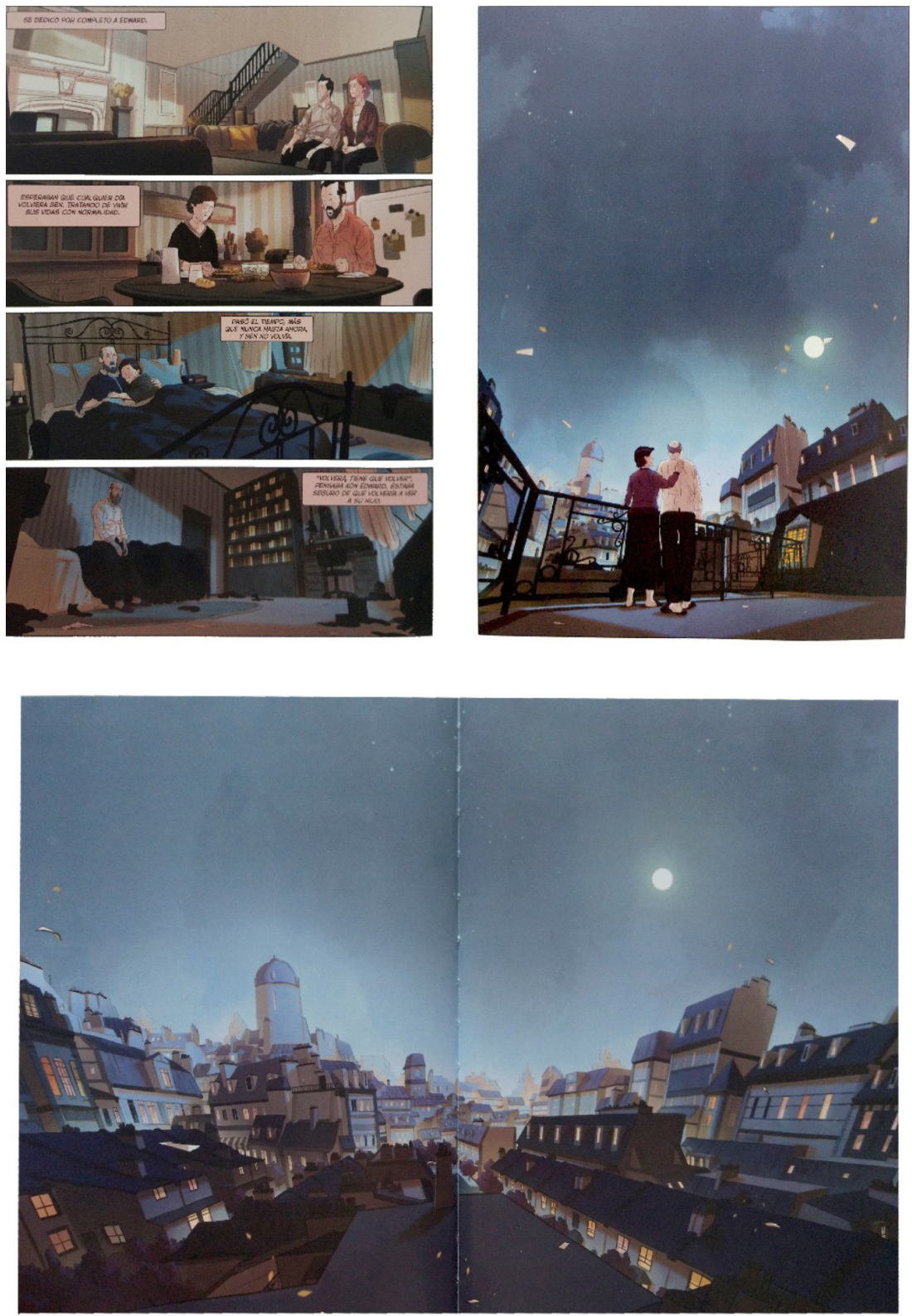

Figura 5. Páxinas 114-117 de Los que quedan (2019).

Pasados moitos anos, Ben regresa por última vez xa feito un mozo. Antes de marchar, Wumple fala con el para manifestarlle que medrara demasiado, que era case adulto e por conseguinte a súa maxia estaba desaparecendo por completo, polo que non pode volver viaxar con el. Ante a consternación do neno, Wumple explícalle que é demasiado perigoso e que volverá buscalo cando sexa seguro. Logo disto Ben baixa buscar o seu pai pero non atopa a 
ninguén, só unha carta de Laura onde explica que Edward o esperara até o último momento, que falecera uns anos atrás e que estaba enterrado xunto á súa nai. Tamén lle di que se necesita axuda pode chamar á APNA e preguntar por Arthur, quen pode incluso poñelo en contacto coa propia Laura se así o desexa. Uns días máis tarde, Ben vai á sede da APNA e no lugar de a Arthur atopa a Arnold, o seu fillo, quen presidira a asociación dende a morte do pai, e tamén a dúas nenas aventureiras xa convertidas en adultas, Anne e Helen. Dinlle que non se ten que preocupar xa que a asociación lle pode dar diñeiro para o seu sustento e axudarlle a rematar os estudos e atopar un traballo, aínda que Ben insiste en que só necesita apoio durante un tempo porque confía na palabra de Wumple e en que regresará por el. Arnold explícalle que é posíbel que iso nunca suceda xa que os seres fantásticos usan os nenos co obxectivo de salvar os seus reinos para despois esquecelos, mentres as dúas mulleres intercambian miradas cómplices de preocupación pola decepción que estaban seguras que ía sufrir Ben co tempo:

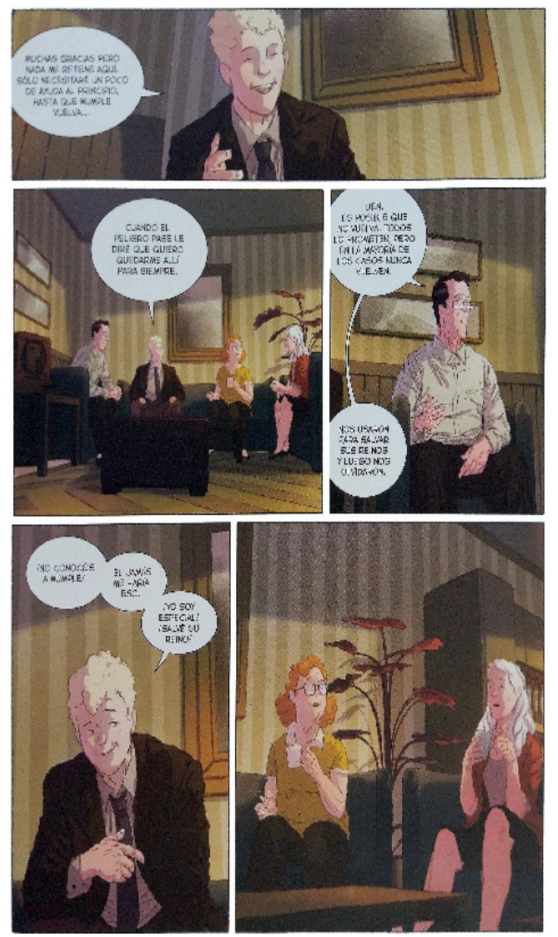

Figura 6. Páxina 125 de Los que quedan (2019).

As dúas últimas escenas mostran o final das dúas derradeiras vítimas da tan extraordinaria aventura que emprendera Ben sendo un neno. Por unha parte, a obra presenta unha páxina completa onde se recollen os minutos 
finais de Lesstone a través dunha serie de viñetas guiadas polas intervencións en globos de cor turquesa clara e delimitados por pequenos trazos ondulados rematados en pico que recollen as intervencións da reporteira que cobre a morte do periodista nun programa televisado (p. 126):
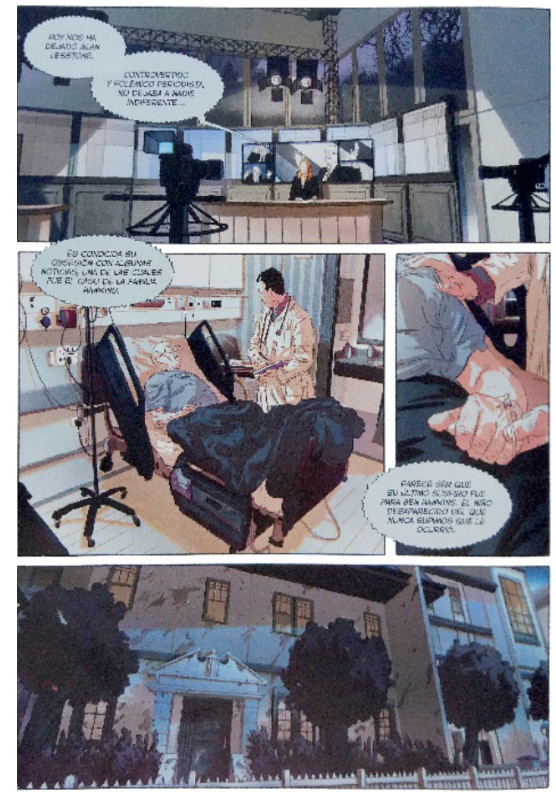

Figura 7. Páxina 126 de Los que quedan (2019).

Por último, a historia remata focalizada no personaxe de Ben, do mesmo xeito que comezara, pero nunha situación totalmente distinta. Convertido xa nun home, as dúas páxinas finais mostran o tráxico destino do personaxe que vive á espera de que Wumple volva por el, deprimido, desesperado e sen ganas de vivir, igual que os seus pais anos atrás. Como indica o propio narrador, Ben está só e o seu conto non ten un final feliz (pp. 127-128) (figura 8).

Unha vez rematada a descrición exhaustiva das distintas escenas que compoñen o arco argumental da historia, o procesamento dos resultados indícanos que a evolución dos pareceres dos personaxes da historia, quen guían a maneira na que se artella a trama, van oscilando entre o apoio ou rexeitamento dos protagonistas, Ben e os adultos responsables del (en primeiro lugar os pais, Edward e Susan, e logo o pai e Laura, a súa nova parella) e do seu principal antagonista, o periodista Alan Lesstone. Estes cambios actitudinais determinan en gran medida os altos e baixos destes personaxes, mais nada pode evitar o final desgraciado de todos eles, que rematan pasando ao esque- 
cemento. Ademais, o enfrontamento que se desliga en todo momento entre o mundo da adultez, cheo de prexuízos, desconfiado, monótono e coartador, e o da infancia, emocionante, pero tamén en certa medida inconsciente e irresponsábel, vese reforzado pola presenza e evolución do fantástico, territorio vedado para os adultos.
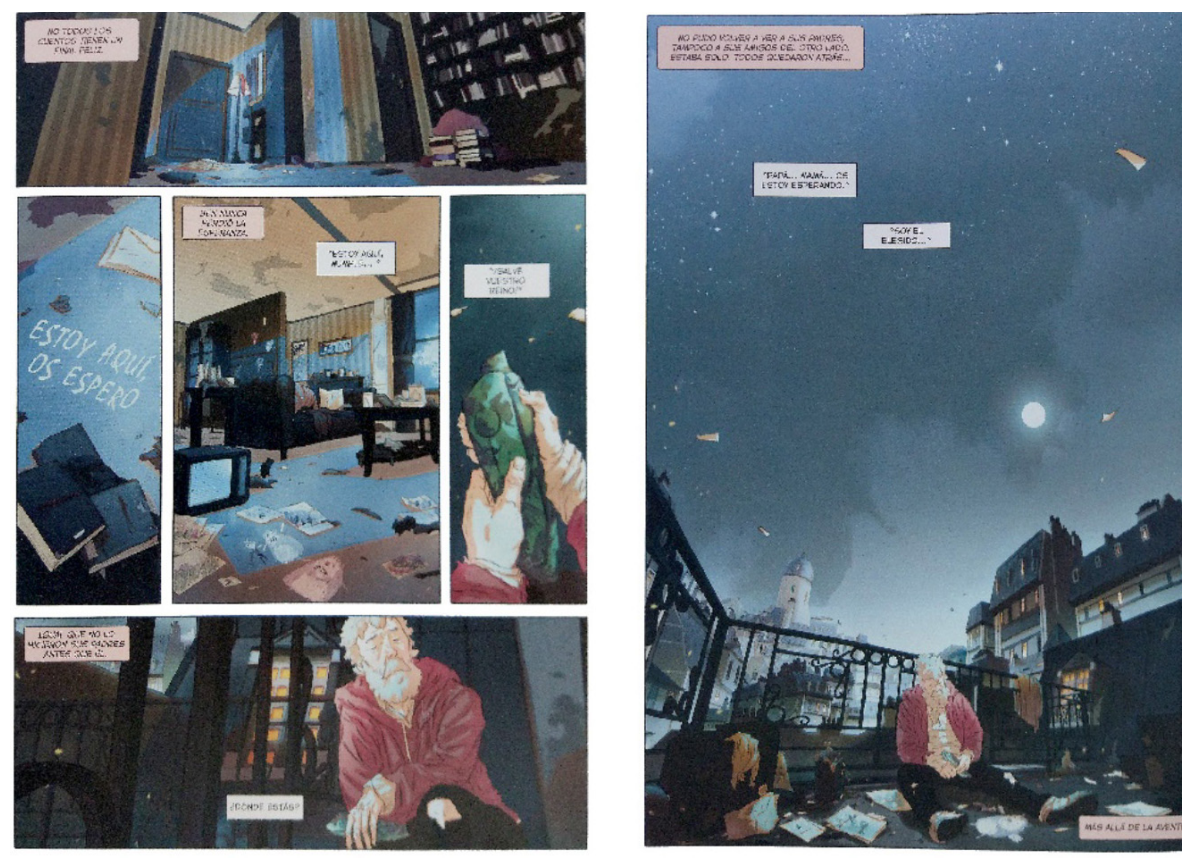

Figura 8. Páxinas 127-128 de Los que quedan (2019).

\section{Discusión e conclusións}

A discusión levada a cabo despois da análise dos resultados obtidos permítenos relacionar unha serie de conclusións que responden aos obxectivos desligados do interese principal da nota de indagar a maneira na que se artella o diálogo intertextual entre a literatura e o cómic no caso concreto da obra de Busquet e Xöul.

Por unha parte, Los que quedan cumpre os catro niveis de descrición da novela gráfica mencionados na introdución do traballo: a nivel formal, a obra dá conta do estilo característico do autor da narración gráfica, cuxa progresión vai xogando con distintos planos e alterna os diálogos dos personaxes con escenas onde a voz narradora toma totalmente o control para propor- 
cionar información privilexiada ao lectorado e complementar o dramatismo dalgunha das escenas máis tensas da obra; a nivel de contido, aínda que os eventos relatados xiran ao redor da intrusión do fantástico, a historia parte da naturalización do "imposible" como algo "real" e focalízase en dar conta da evolución das reaccións dos adultos dos distintos ámbitos identificados (privado, público e restrinxido) ao longo das viaxes de ida e volta do protagonista; con respecto ao nivel de formato de publicación, en efecto estamos ante unha novela gráfica que aposta polo formato libro en todos os aspectos, tratándose dun volume único dunha extensión considerable. Finalmente, a obra foi publicada por unha editorial especializada no mundo do cómic que comezou apostando polo manga e agora traballa na recuperación de grandes clásicos do cómic mentres amplía o seu catalogo con propostas máis actuais da banda deseñada.

En canto ao diálogo intertextual que estabelece coas estruturas clásicas dos mundos abertos e das fantasías de portais, os resultados evidencian que a novela gráfica parte da deconstrución da maneira habitual de desenvolver o arco argumental destas tipoloxías de obras no sistema literario infantil e xuvenil a partir de tres cambios fundamentais: o traslado da focalización da historia cara aos adultos, os cales se converten nos verdadeiros protagonistas, especialmente no caso dos pais de Ben, mais tamén se presta especial atención a como van evolucionando os demais secundarios e a como se van influenciando mutuamente; por outra parte, no lugar de seguir a viaxe do neno-protagonista ao mundo secundario-fantástico, desta volta a historia está sempre contextualizada no mundo primario e o único acceso que temos a el é a través do ser que irrompe na normalidade de Ben, das historias do propio rapaz e doutros coma el que tamén realizaron as mesmas viaxes. Mentres a veracidade do fantástico non remata por ser un aspecto fundamental para moitas das obras clásicas que narran a viaxe a mundos secundarios, no caso de Los que quedan a trama aséntase sobre a naturalización do fantástico e do tratamento adulto do proceso.

Para rematar, consideramos interesante destacar que á luz do estudo realizado podemos constatar que as narrativas fantásticas poden ser construídas de maneira análoga independentemente de se se dirixen a adultos ou á infancia, de xeito que a pertenza a un ou outro sistema vén determinada polo tratamento que se fai da temática así como da perspectiva adoptada. O afastamento consciente dos intereses da infancia e o desprazamento da focalización do relato cara aos adultos supón 
que a historia dun neno que viaxa a un mundo fantástico tras a chegada dun ser que lle roga que sexa o salvador do seu reino sexa catalogada como unha novela gráfica para adultos. Ademais, este cambio consciente na realización da proposta tamén se ve reforzado pola aposta dun estilo gráfico sobrio, cores de baixa saturación cunha gran predominancia dos tons escuros, e ambientes taciturnos. En efecto, esta é unha proba máis dos xogos intertextuais e intermediais da literatura coas distintas artes, como o cine, as artes plásticas, a música ou o cómic, que se poden dar entre distintos sistemas sen importar o público obxectivo, de xeito que o produto resultante será acollido por un ou outro sistema en función da propia idiosincrasia do relato e da toma de decisións conscientes dos seus creadores.

\section{Bibliografía}

Attebery, B. (1980). The fantasy tradition in American Literature. Indiana University Press.

Attebery, B. (1992). Strategies of fantasy. Indiana University Press.

Attebery, B. (2014). Stories about stories: fantasy and the remaking of myth. Ofxord University Press.

Baetens, J. e Frey, H. (2015). The Graphic Novel. An Introduction. Cambridge University Press.

Bardin, L. (1991). El análisis de contenido. Akal.

Bendit Saltzman, E. (2017). Novel to Graphic Novel. En S. Tabachnick (Ed.), The Cambridge Companion to The Graphic Novel (pp. 144-159). Cambridge University Press.

Booker, M.-K. (2017). Graphic Novel into Film. En S. Tabachnick (Ed.), The Cambridge Companion to The Graphic Novel (pp. 160-174). Cambridge University Press.

Busquet, J. e Xöul, A. (2019). Los que quedan. Ponent Mon.

Cáceres, P. (2003). Análisis cualitativo de contenido: una alternativa metodológica alcanzable. Psicoperspectivas: Revista de la Escuela de Psicología, 2 (1), 53-82. https:// doi.org/10.5027/psicoperspectivas-Vol2-Issue1-fulltext-3.

Camacho Guizado, E. (2003). Acerca de los géneros de lo fantástico, lo maravilloso y la mitoficción. Literatura: teoría, historia, crítica, 5, 61-78. https://revistas.unal. edu.co/index.php/lthc/article/view/45022. 
Carter, J.-B. (2017). Learning from the Graphic Novel. En S. Tabachnick (Ed.), The Cambridge Companion to The Graphic Novel (pp. 192-209). Cambridge University Press.

Chacón, A.-M. (2015). La multimodalidad del cómic: una experiencia de lectura de imágenes en los primeros grados escolares. Enunciación, 20 (2), 10-26. https:// doi.org/10.14483/udistrital.jour.enunc.2015.2.a02.

Chacón, A.-M. (2016). El cómic: una experiencia de lectura que forma, transforma o informa al sujeto. Educación y ciudad, 30, 119-128. https://doi.org/10.36737/0 1230425.v.n30.2016.1592.

Clute, J. y Grant, J. (Eds.) (1997). The Encyclopedia of Fantasy. Orbit.

Conde Aldana, J.-A. (2019). Del cómic a la novela gráfica: mutaciones editoriales de la historieta colombiana en el siglo XXI. Mitologías boy, 20, 61-77. https://doi. org/10.5565/rev/mitologias.662.

Duncan, R. e Smith, M.-J. (2017). How the Graphic Novel Works. En S. Tabachnick (Ed.), The Cambridge Companion to The Graphic Novel (pp. 8-25). Cambridge University Press.

Francescutti, P. (2019). La narración audiovisual como documento social e histórico: enfoques teóricos y métodos analíticos. EMPIRIA. Revista de Metodología de Ciencias Sociales, 45, 137-161. https://doi.org/10.5944/empiria.42.2019.23255

Furtado, F. (1980). A Construção do Fantástico na Narrativa. Livros Horizonte.

Gagliardi, L. (2020). ¿Literatura fantástica según quién? Diferentes aristas de un problema. Catalejos. Revista sobre lectura, formación de lectores y literatura para niños, 5 (10), 16-41. https://fh.mdp.edu.ar/revistas/index.php/catalejos/article/ view/3976/4288

García Conde-Maestre, J. (2020). Cine en viñetas y cómic en celuloide: retroalimentación en el universo de Frank Miller. Quaderns, 15, 45-63. https://doi. org/10.14198/QdCINE.2020.15.04.

García, S. (2010). La novela gráfica. Astiberri.

González de la Llana, N. (2020). El relato del monstruo en el Frankenstein de Gris Grimly. Tonos Digital, 1 (38), 1-9. https://www.um.es/tonosdigital/znum38/indice38.htm.

González Salvador, A. (1984). De lo fantástico y de la literatura fantástica. Anuario de Estudios Filológicos, VII, 208-226. http://dehesa.unex.es/bitstream/handle/10662/3684/0210-8178_7_207.pdf? sequence=1\&isAllowed=y. 
G-Pedreira, Rocío (2019). A complexidade do modelo fantástico intertextual de Cada corazón, un umbral. Boletín Galego De Literatura, 54, 13-28. https://doi. org/10.15304/bgl.54.5942

Held, J. (1985): Los niños y la literatura fantástica, función y poder de lo imaginario. Paidós.

Jackson, R. (1986). Fantasy: literatura y subversión. Catálogos Editora.

Krippendorff, K. (1990). Metodología de análisis de contenido. Teoría y Práctica. Paidós Comunicación.

Levy, M. e Mendlesohn, F. (2016). Children's Fantasy Literature. An introduction. Cambridge University Press.

Lizarazú Bernal, B.-C. (2018). ¿Cómo propiciar en los estudiantes una lectura inferencial? Infancias Imágenes, 17 (1), 109-116. https://doi. org/10.14483/16579089.11419.

López Hernández, A. (2003). El análisis cronológico-secuencial del documento fílmico. Documentación de las Ciencias de la Información, 26, 261-294. https://revistas. ucm.es/index.php/DCIN/article/view/DCIN0303110261A.

López Noguero, F. (2002). El análisis de contenido como método de investigación. Revista de Educación, 4, 167-179. http://rabida.uhu.es/dspace/bitstream/handle/10272/1912/b15150434.pdf.

Mayring, P. (2000). Qualitative Content Analysis. Forum: Qualitative Social Research, 1 (2), art. 20. http://nbn-resolving.de/urn:nbn:de:0114-fqs0002204.

Medina Rodríguez, S. (2020). Las estrategias narrativas y visuales en la obra de Alan Moore. Revista Latente, 18, 251-271. https://doi.org/10.25145/j.latente.2020.18.11.

Mena Araya, A.-E. (2020). Critical Thinking for Civic Life in Elementary Education: Combining Storytelling and Thinking Tools. Revista Educación, 44 (2). https://doi.org/10.15517/revedu.v44i2.39699.

Mendlesohn, F. (2008). Rhetorics of fantasy. Wesleyan University Press.

Nikolajeva, M. (1988). The Magic Code: the use of magical patterns in fantasy for children. Almqvist \& Wiksell International.

Nikolajeva, M. (2012). The development of children's fantasy. En E. James e F. Mendlesohn (Eds.), The Cambridge Companion to Fantasy Literature (pp. 50-61). Cambridge University Press. 
Paré, C. e Soto-Pallarés, C. (2017). El fomento de la lectura de cómics en la enseñanza de las lenguas en Educación Primaria. Ocnos, 16 (1), 134-143. https://doi. org/10.18239/ocnos_2017.16.1.1300.

Pérez Serrano, G. (1994). Investigación cualitativa. Retos e interrogantes I y II. La Muralla.

Pina Arrabal, A. (2020). El tránsito de la literatura al cómic: Ajuar Funerario, de Fernando Iwasaki. Pasavento, VIII (1), 209-236. http://pasavento.com/15_12_ pina_resumen.html.

Pineda, K. (2018). Da narración literaria ao cómic: O Diario de Anne Frank. Boletín Galego de Literatura, 52, 37-52. https://doi.org/10.15304/bgl.52.5020.

Piñeiro-Naval, V. (2020). The content analysis methodology. Uses and applications in communication research on Spanish-speaking countries. Communication \& Society, 33 (3), 1-15. https://doi.org/10.15581/003.33.3.1-15

Richard, S. (2009). El análisis de contenido en la investigación sobre didáctica de la literatura. Enunciación, 14 (1), 145-164. https://doi.org/10.14483/22486798.3284.

Roas, D. (2008). Lo fantástico como desestabilización de lo real: elementos para una definición. En T. López Pellisa, T. e F.-A. Moreno Serrano (Eds.), Ensayos sobre ciencia ficción y literatura fantástica: 1er Congreso Internacional de Literatura Fantástica y Ciencia Ficción, (pp. 94-120). https://e-archivo.uc3m.es/handle/10016/8584.

Roas, D. (2011). Tras los límites de lo real: una definición de lo fantástico. Páginas de Espuma.

Roas, D. (2013). El cuento fantástico. Quimera: Revista de literatura, 354, 22.

Roas, D. (Comp.) (2001). Teorías de lo fantástico. Arco Libros.

Roas, D. (Coord.) (2018). Brumal. Revista de Investigación sobre lo Fantástico: Horror and the Fantastic. Brumal. Revista de Investigación sobre lo Fantástico, 6 (2), número monográfico. https://doi.org/10.5565/rev/brumal.580.

Sánchez Noriega, J.-L. (2000). De la literatura al cine. Teoría y análisis de la adaptación. Paidós Ibérica.

Stam, R. (2000). Beyond Fidelity: The Dialogics of Adaptation. En J. Naremore (Ed.), Film Adaptation (versión electrónica). Rutgers University Press.

Sulbarán Piñeiro, E. (2000). El análisis del film. Entre la semiótica del relato y la narrativa fílmica. Opción: Revista de Ciencias Humanas y Sociales, 31, 44-71. https:// dialnet.unirioja.es/descarga/articulo/2474953.pdf. 
Tabachnick, S. (2017). From Comics to the Graphic Novel: William Hogarth to Will Eisner. En S. Tabachnick (Ed.), The Cambridge Companion to The Graphic Novel (pp. 26-40). Cambridge University Press.

Todorov, T. (1994). Introducción a la literatura fantástica. Ediciones Coyoacán.

Trabado, J.-M. (2012). Antes de la novela gráfica. Clásicos del cómic en la prensa norteamericana. Cátedra.

Weschenfelder, G. (2020). Quadrinhos de super-herói em sala de aula. Aula, 26, 131147. http://dx.doi.org/10.14201/aula202026131147. 